\title{
Metallothionein III (MT3) is a putative tumor suppressor gene that is frequently inactivated in pediatric acute myeloid leukemia by promoter hypermethylation
}

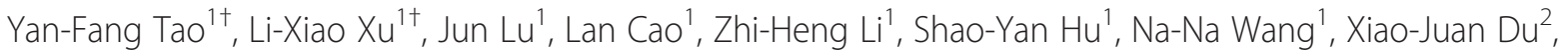 \\ Li-Chao Sun ${ }^{3}$, Wen-Li Zhao ${ }^{1}$, Pei-Fang Xiao ${ }^{1}$, Fang Fang ${ }^{1}$, Yan-Hong Li ${ }^{1}$, Gang Li ${ }^{1}$, He Zhao ${ }^{1}$, Yi-Ping Li ${ }^{1}$, \\ Yun-Yun $\mathrm{Xu}^{1}$, Jian $\mathrm{Ni}^{4}$, Jian Wang ${ }^{1}$, Xing Feng ${ }^{1 *}$ and Jian Pan ${ }^{1 *}$
}

\begin{abstract}
Background: Acute myeloid leukemia (AML) is the second most common form of leukemia in children. Aberrant DNA methylation patterns are a characteristic feature in various tumors, including AML. Metallothionein III (MT3) is a tumor suppresser reported to show promoter hypermethylated in various cancers. However, the expression and molecular function of MT3 in pediatric AML is unclear.

Methods: Eleven human leukemia cell lines and 41 pediatric AML samples and 20 NBM/ITP (Norma bone marrow/ Idiopathic thrombocytopenic purpura) control samples were analyzed. Transcription levels of MT3 were evaluated by semi-quantitative and real-time PCR. MT3 methylation status was determined by methylation specific PCR (MSP) and bisulfite genomic sequencing (BSG). The molecular mechanism of MT3 was investigated by apoptosis assays and PCR array analysis.
\end{abstract}

Results: The MT3 promoter was hypermethylated in leukemia cell lines. More CpG's methylated of MT3 was observed 39.0\% pediatric AML samples compared to 10.0\% NBM controls. Transcription of MT3 was also significantly decreased in AML samples compared to NBM/TTP controls $(P<0.001)$; patients with methylated MT3 exhibited lower levels of MT3 expression compared to those with unmethylated MT3 $(P=0.049)$. After transfection with MT3 lentivirus, proliferation was significantly inhibited in AML cells in a dose-dependent manner $(P<0.05)$. Annexin $V$ assay showed that apoptosis was significantly upregulated MT3-overexpressing AML cells compared to controls. Real-time PCR array analysis revealed 34 dysregulated genes that may be implicated in MT3 overexpression and apoptosis in AML, including FOXO1.

Conclusion: MT3 may be a putative tumor suppressor gene in pediatric AML. Epigenetic inactivation of MT3 via promoter hypermethylation was observed in both AML cell lines and pediatric AML samples. Overexpression of MT3 may inhibit proliferation and induce apoptosis in AML cells. FOXO1 was dysregulated in MT3-overexpressing cells, offering an insight into the mechanism of MT3-induced apoptosis. However, further research is required to determine the underlying molecular details.

Keywords: Metallothionein III, Pediatric acute myeloid leukemia, Methylation, Tumor suppressor

\footnotetext{
*Correspondence: xing_feng66@hotmail.com; panjian2008@163.com

${ }^{\dagger}$ Equal contributors

'Department of Hematology and Oncology, Children's Hospital of Soochow University, Suzhou, China

Full list of author information is available at the end of the article
} 


\section{Introduction}

Acute myeloid leukemia (AML) is a type of cancer in the myeloid cell. It is the most common form of acute leukemia in adults and the second most common form of leukemia in children after acute lymphoblastic leukemia (ALL) [1,2]. The incidence of AML increases with age and is characterized by the rapid growth of abnormal white blood cells which accumulate in the bone marrow and interfere with the production of normal blood cells [3].

DNA methylation is an important regulator of gene transcription. It is an epigenetic modification that typically occurs at CpG (cytosine-phosphate-guanine) sites in mamalian cells. It is catalyzed by DNA methyltransferase which results in the conversion of the cytosine residue to 5-methylcytosine, leading to the formation of Me-CpG [4]. Alterations in DNA methylation frequently occur during cell development and are common in tumors. Aberrant DNA methylation patterns have been reported in a variety of cancers including AML $[5,6]$. Hypermethylation within the promoter regions of tumor suppressor genes leads to gene silencing, and global hypomethylation has also been recognized as a cause of oncogenesis $[7,8]$. As such, the role of methylation in carcinogenesis has been the focus of considerable research. However, the mechanisms leading to aberrant DNA methylation are poorly understood.

Genome-wide studies have been performed to obtain details on the genome and epigenome in various solid tumors. Examination of clonal evolution patterns have suggested that these may shape epigenetic dysregulation in AML. Investigations on genome-wide methylation in AML have shown variations in methylation patterns between AML and normal healthy tissues [9-11]. Although several studies have found that molecular subtypes in AML can exhibit highly distinct DNA methylation profiles [12,13], a small set of common genes have also been shown to exhibit consistent aberrant methylation across several hundred cases of AML [14,15], such as PML-RAR $\alpha$ and AML1-ETO $[12,13,16]$. Together, these findings implicate distinct aberrant DNA methylation patterns in the pathogenetic processes in cancer, rather than evolving homogeneously across cancer types,

Deep sequencing of patients with different myeloid malignancies has revealed recurrent mutations in epigenetic regulator proteins, such as DNMT3A and TET2, and several major driver mutations in normal karyotype AML $[17,18]$. Functional studies of these mutations have revealed specific methylation signatures. These mutations carry prognostic relevance and are likely to be contributors to AML pathogenesis.

Metallothionein (MT) is a family of cysteine-rich, low molecular weight $(500-14,000 \mathrm{Da})$ proteins [19]. Ten functional isoforms of MTs have been identified, which are divided into four classes (MT1-4) based on small differences in protein sequences and characteristics. MTs have been proposed to play important roles in protecting against DNA damage, apoptosis and oxidative stress. MT3 was first identified as a neuronal growth inhibitory factor [20]. In vitro studies have demonstrated that MT3 can inhibit neurite formation and survival in neurons [20]. It has been shown to protect against apoptotic neuronal death in the brains of patients with Alzheimer's disease and in the hippocampus of SAMP8 mice, suggesting that MT3 may inhibit the development of neurodegeneration and may influence neuronal regeneration during the recovery process $[21,22]$. Its endogenous overexpression in glial and tumor cells stably transfected with MT3 was found to inhibit cell growth. In addition, MT3 plays a role in regulating lysosomal functions; in the absence of MT3, reductions in specific lysosomal enzymes associated with decreased autophagic flux have been reported [23].

In relation to cancer, downregulation of MT3 has been reported as one of 17 changes in gene expression which are associated with metastasis and poor clinical outcome in a range of solid tumors, including gastric cancer [24] and primary esophageal squamous cell carcinoma (SCC) [25]. This was supported by the observation that treatment with 5-aza-2'-deoxycytidine, an inhibitor of DNA methylation reduced the degree of methylation and increase the level of MT3 expression, in esophageal SCC cell lines [25]. Significant downregulation of MT3 has been most frequently reported in tumors that exhibiting MT3 methylation, suggesting that MT3 may act as a tumor suppresser via promoter hypermethylation [26].

However, reports on the methylation status of MT3 in the blood system are rare, and its expression and role in pediatric AML remains unclear. The aim of this study was to analyze the methylation profile and molecular function of MT3 in pediatric AML.

\section{Methods \\ Cell lines}

Leukemia cell lines HL-60, MV4-11, U937, DAMI and K562 were obtained from the American Type Culture Collection (ATCC). CCRF, Raji, Jurkat, 697 and SHI-1 cell lines (gifts from Professor Wang Jian-Rong, The Cyrus Tang Hematology center of Soochow University). All cell lines were maintained at $37^{\circ} \mathrm{C}$ in the RPMI 1640 (GibcoR, Life Technologies, Carlsbad, CA) supplemented with $10 \%$ fetal bovine serum (Invitrogen, Life Technologies, Carlsbad, CA).

\section{Patients and samples}

Bone marrow specimens were obtained at the time of diagnosis during routine clinical assessment of 41 pediatric patients with AML, who presented at the Department of Hematology and Oncology, Children's Hospital of Soochow University between 2000 and 2010. Ethical 
approval was provided by the Children's Hospital of Soochow University Ethics Committee (No. SUEC2000021), and informed consent was obtained from the parents or guardians. AML diagnosis was made in accordance with the revised French-American-British (FAB) classification. The main clinical and laboratory features of the patient cohort are summarized in Table 1. Additionally, bone marrow samples from 12 healthy donors and 8 patients with Idiopathic thrombocytopenic purpura (ITP) were analyzed as controls. Bone marrow mononuclear cells (BMNCs) were isolated using Ficoll solution within $2 \mathrm{~h}$ after bone marrow samples harvested and immediately subjected for the extraction of total RNA and genomic DNA.

\section{$\mathrm{CD} 34^{+}$cell purification}

For CD34 ${ }^{+}$cell selection, the Miltenyi immunoaffinity device (VarioMACS 130-046-703) was used according to the manufacturer's instructions (Miltenyi Biotech, Auburn, CA). Briefly, the CD $34^{+}$cells are magnetically labeled with CD34 MicroBeads. Then, the cell suspension is loaded onto a MACSR Column which is placed in the magnetic field of a MACS Separator. The magnetically labeled $\mathrm{CD}_{34}{ }^{+}$cells are retained within the column. The unlabeled cells run through; $\mathrm{CD}_{4} 4^{+}$cells were adsorbed on the magnetic poles. After removing the column from the magnetic field, the magnetically retained $\mathrm{CD}_{4} 4^{+}$cells can be eluted as the positively selected cell fraction.

\section{Sodium bisulfite modification of genomic DNA}

High-molecular-weight genomic DNA was extracted from cell lines and biopsies by a conventional phenol/chloroform method. The sodium bisulphite modification procedure was as described [27] with slight modification. In brief, $600 \mathrm{ng}$ of genomic DNA was denatured in $3 \mathrm{M} \mathrm{NaOH}$ for
15 min at $37^{\circ} \mathrm{C}$, then mixed with 2 volumes of $2 \%$ lowmelting-point agarose. Agarose/DNA mixtures were then pipetted into chilled mineral oil to form agarose beads. Aliquots of $200 \mu \mathrm{l}$ of $5 \mathrm{M}$ bisulphite solution (2.5 M sodium metabisulphite, $100 \mathrm{mM}$ hydroquinone, both Sigma, USA) were added into each tube containing a single bead. The bisulphite reaction was then carried out by incubating the reaction mixture for $4 \mathrm{~h}$ at $50^{\circ} \mathrm{C}$ in the dark. Treatments were stopped by equilibration against $1 \mathrm{ml}$ of TE buffer, followed by desulphonation in $500 \mu \mathrm{l}$ of $0.2 \mathrm{M} \mathrm{NaOH}$. Finally, the beads were washed with $1 \mathrm{ml}$ of TE buffer and directly used for PCR.

\section{Methylation-specific PCR}

The methylation status of the MT-3 promoter region was determined by methylation-specific PCR. Primers distinguishing unmethylated $(\mathrm{U})$ and methylated $(\mathrm{M})$ alleles were designed to amplify the sequence:

MT-3 M-forward: 5- TTAAGCGTATAAACGGAAA GAGC -3;

MT-3 M-reverse: 5- AAAACAAATCTCAAAATCCA TATCG -3;

MT-3 U-forward: 5- TTTAAGTGTATAAATGGAAA GAGTGG -3;

MT-3 U-reverse: 5- AACAAATCTCAAAATCCATAT CAAA -3 .

Each PCR reaction contained 20 ng of sodium bisulphitemodified DNA, 250 pmol of each primer, 250 pmol deoxynucleoside triphosphate, $1 \times$ PCR buffer, and one unit of ExTaq HS polymerase (Takara, Tokyo) in a final reaction volume of $20 \mu \mathrm{l}$. Cycling conditions were initial denaturation at $95^{\circ} \mathrm{C}$ for $3 \mathrm{~min}, 40$ cycles of $94^{\circ} \mathrm{C}$ for $30 \mathrm{~s}, 60^{\circ} \mathrm{C}$ (M) or $58^{\circ} \mathrm{C}(\mathrm{U})$ for $30 \mathrm{~s}$, and $72^{\circ} \mathrm{C}$ for $30 \mathrm{~s}$. For each set of

Table 1 Correlation between MT3 methylation status and clinicopathological features in pediatric AML patients

\begin{tabular}{|c|c|c|c|c|}
\hline \multirow[t]{2}{*}{ Clinical and pathologic features } & \multicolumn{4}{|c|}{ Median (range) } \\
\hline & Methylated $(n=16)$ & Unmethylated $(n=25)$ & Total patients $(n=41)$ & $P$-value \\
\hline Age (years) & $5.17(1-13)$ & $6.72(1-11)$ & $6.16(1-13)$ & 0.622 \\
\hline Gender (male/female ratio) & $10 / 6$ & $11 / 14$ & $21 / 20$ & \\
\hline WBC: median; range $\left(10^{9} / \mathrm{L}\right)$ & $14.1(0.8-51.1)$ & $18.2(0.8-43.6)$ & $16.6(0.8-51.1)$ & 0.757 \\
\hline Hemoglobin: median; range ( $g / L)$ & $70.1(32-176)$ & $75.2(32-107)$ & $73.2(32-176)$ & 0.812 \\
\hline Platelet count: median; range $\left(10^{9} / \mathrm{L}\right)$ & $57.2(12-310)$ & $70.2(23-273)$ & $65.13(12-310)$ & 0.438 \\
\hline \multicolumn{5}{|l|}{ FAB subtype ( $n=$ number of patients) } \\
\hline M1 & 2 & 4 & 6 & \\
\hline M2 & 5 & 5 & 11 & \\
\hline M3 & 7 & 4 & 11 & \\
\hline M4 & 3 & 2 & 5 & \\
\hline M5 & 3 & 5 & 8 & 0.733 \\
\hline MT3 transcript & 10.65 & 19.23 & 16.37 & $0.049^{*}$ \\
\hline
\end{tabular}

$F A B$, French-American-British; $W B C$, White blood cells. ${ }^{*} \mathrm{P}<0.05$. 
methylation-specific PCR reactions, in vitro-methylated genomic DNA treated with sodium bisulphite served as a positive methylation control. PCR products were separated on $4 \%$ agarose gels, stained with ethidium bromide and visualized under UV illumination. For cases with borderline results, PCR analyses were repeated.

\section{Bisulfite genomic sequencing}

Bisulfite genomic sequencing (BGS) was performed as previously described [28]. BGS primers were from +427 to +672 including 15 CpGs. MT-3 F: 5- AGGGAGATTTGG TATTTTATTTTTT-3 and MT-3 R: 5- ACCTAACTA TCTCTCCACATCCTAC-3. Amplified BGS products were TA-cloned; and five to six randomly chosen colonies were sequenced. DNA sequences were analyzed with QUMA Analyzer. (http://quma.cdb.riken.jp/).

\section{Leukemia cell cells treated with 5-aza-2'-deoxycytidine}

De-methylation was induced with 5-aza-dC (5-Aza, SigmaAldrich, St Louis, MO, USA) treatment at a concentration that induced de-methylation of the DNA without killing the cells. Culture media for HL-60 and MV4-11 cells contained $5 \mu \mathrm{M}$ 5-Aza. DNA and RNA were extracted after 72 hours of 5-Aza treatment for the following analysis.

\section{Quantitative reverse-transcription PCR for MT-3}

Quantitative real-time PCR was performed to determine the expression levels of MT-3 genes. Total RNA was reverse transcribed using the Reverse Transcription Kit, according to the manufacturer's protocol (Applied Biosystems Inc., Foster City, CA). The real time PCR primers used to quantify GAPDH expression were: F: 5 '-AGAAG GCTGGGGCTCATTTG-3' and R: 5'-AGGGGCCATC CACAGTCTTC-3' and for MT-3 were: F: 5' -ACACA CAGTCCTTGGCACAC-3' and R: 5'-AAGTGCGAGG GATGCAAAT-3'. Expression of MT-3 was normalized to endogenous GAPDH expression.

\section{MT-3 lentiviral expression constructs and lentivirus production}

Briefly, an approximately 250 bp fragment containing the human MT-3 gene was directly synthesized, and cloned into the pMD18-T vector. Positive clones were confirmed by sequencing and subcloned into the pLVXIRES-ZsGreen vector (Clontech). The vector plasmids, pLVX-IRES-ZsGreen1, pLP1, pLP2 and pLP/VSVG were amplified in E.Coli and purified using the Endofree Maxiprep Kit (Qiagen). $270 \mu \mathrm{g}$ of transfer vector, $176 \mu \mathrm{g}$ of pLP1, $95 \mu \mathrm{g}$ of pLP/VSVG and $68 \mu \mathrm{g}$ of pLP2 was mixed with $0.25 \mathrm{M} \mathrm{CaCl} 2$ (Sigma) and added to same volume of $2 \times$ HEPES (Sigma) and mixed while bubbling for $20 \mathrm{~min}$ to allow a precipitate to form. This was then added to a $175 \mathrm{~cm} 2$ flask of approximately $60 \%$ confluent $293 \mathrm{~T}$ cells containing $20 \mathrm{~mL}$ DMEM supplemented with $10 \%$ fetal calf serum, $100 \mathrm{U} / \mathrm{mL}$ penicillin, $100 \mu \mathrm{g} / \mathrm{mL}$ streptomycin and $2 \mathrm{mM}$ glutamine and incubated for $48 \mathrm{~h}$ at $37^{\circ} \mathrm{C}$ in $5 \% \mathrm{CO}$. The supernatant was centrifuged at $1,700 \mathrm{~g}$ for $10 \mathrm{~min}$ to pellet cell debris, and ultracentrifuged at 121,603 $\mathrm{g}$ for $2 \mathrm{~h}$. The pellet containing concentrated virus was resuspended in DMEM without supplements and stored at $-80^{\circ} \mathrm{C}$.

\section{Cell proliferation analysis}

Acute myeloid leukemia cells were seeded in 96-well plates at $2 \times 10^{4}$ cells per well. 20 ul CCK-8(Dojindo Molecular Technologies, Japan) was added to each well and incubated at $37^{\circ} \mathrm{C}$ for a further 4 hours. The optical density (OD) values were measured at $450 \mathrm{~nm}$ on a scanning multi-well spectrophotometer (BioRad Model 550, USA). Compared with the control group, Cell proliferation was calculated as proliferation values. All experiments were performed in triplicate and repeated twice. The results were analyzed using ANOVA and the Student-Newman-Keuls tests, $p<0.05$ were considered significant.

\section{Apoptosis assay}

Apoptosis assay was according to the manual operation of BD Annexin V Staining Kit (Cat: 556420, BD Biosciences, Franklin Lakes and NJ USA). Briefly, wash cells twice with cold PBS and then resuspend cells in $1 \times$ Binding Buffer at a concentration of $\sim 1 \times 10^{6}$ cells $/ \mathrm{ml}$. Transfer $100 \mu \mathrm{l}$ of the solution $\left(\sim 1 \times 10^{5}\right.$ cells $)$ to a $5 \mathrm{ml}$ culture tube. Add Annexin V and PI $5 \mu \mathrm{l} /$ test. Gently mix the cells and incubate for $15 \mathrm{~min}$ at RT in the dark. Add $400 \mu \mathrm{l}$ of $1 \times$ Binding Buffer to each tube. Analyze by flow cytometry as soon as possible (within 1 hour).

\section{Western blot analysis}

For western blot analysis, cellular proteins were extracted in $40 \mathrm{mM}$ Tris- $\mathrm{HCl}(\mathrm{pH} 7.4)$ containing $150 \mathrm{mM} \mathrm{NaCl}$ and $1 \%(\mathrm{v} / \mathrm{v})$ Triton X-100, supplemented with a cocktail of protease inhibitors. Equal amounts of protein were resolved on 12\% SDS-PAGE gels, and then transferred to a PVDF membrane (Millipore, Bedford, MA). Blots were blocked and then probed with antibodies against MT-3 (1:1000, Abcam, Cambridge, MA Office, USA), PARP (1:1000, Cell Signaling Technology, Inc. Danvers, MA), FOXO1 (1:1000, Cell Signaling Technology, Inc. Danvers, MA), CDKN1A (1:1000, Cell Signaling Technology, Inc. Danvers, MA), GAPDH (1:5000, Sigma, St. Louis, MO). After washing, the blots were incubated with horseradish peroxidase-conjugated secondary antibodies and visualized by enhanced chemiluminescence kit (Pierce, Rockford, IL). Protein bands were visualized after exposure of the membrane to Kodak X-ray film. 


\section{Real-time PCR array analysis}

For RNA extraction, cells were immediately submerged in $2 \mathrm{ml}$ Trizol (Invitrogen Co., NY, USA), stored at $-80^{\circ} \mathrm{C}$ until further processed. A volume of $1 \mathrm{ml}$ of each sample was spun at $4^{\circ} \mathrm{C}$ for $15 \mathrm{~min}$ at $12,000 \mathrm{~g}$ to remove debris and DNA, $1 \mathrm{ml}$ of supernatant was mixed with $200 \mathrm{ul}$ chloroform, shaken for 15 seconds, incubated at Room Temperature for 2-3 minutes and spun for 10 minutes at $12,000 \mathrm{~g}$ at $4^{\circ} \mathrm{C}$. RNA was precipitated by adding $500 \mathrm{ul}$ of the aqueous phase to an equal volume of isopropanol and spun at $14,000 \mathrm{~g}$ at $4^{\circ} \mathrm{C}$ for 10 minutes. RNA was washed with $75 \%$ ethanol, spun at $14,000 \mathrm{~g}$ at $4^{\circ} \mathrm{C}$ for 10 minutes, dried and resuspended in $40 \mathrm{ul}$ DEPC-treated $\mathrm{H} 2 \mathrm{O}$. The final RNA concentration was determined using a spectrophotometer (Nanodrop 2000) and the purity was assessed by agarose gel electrophoresis. cDNA synthesis was performed on 4 ug of RNA in a $10 \mathrm{ul}$ sample volume using SuperScript II reverse transcriptase (Invitrogen Co., NY, USA) as recommended by the manufacturer. The RNA was incubated with 0.5 ug of oligo (dT)12-18mers primers (Invitrogen Co., NY, USA) for 7 minutes at $70^{\circ} \mathrm{C}$ and then transferred onto ice. Then, $9 \mathrm{ul}$ of a master mix containing $4 \mathrm{ul}$ of SuperScript II buffer, $2 \mathrm{ul}$ of $0.1 \mathrm{M}$ DTT, and $1 \mathrm{ul}$ each of dNTPs stock (10 mM), Rnasin (40 UI) and SuperScript II were added to the RNA sample, spun and incubated at $42^{\circ} \mathrm{C}$ for $60 \mathrm{~min}$ followed by $5 \mathrm{~min}$ at $70^{\circ} \mathrm{C}$ to inactivate the enzyme. cDNA was stored at $-20^{\circ} \mathrm{C}$. Real-time PCR array (SABioscience Human Apoptosis PCR Array PAHS-3012) analysis was performed in a total volume of $20 \mathrm{ul}$ including $2 \mathrm{ul}$ of cDNA, primers $(0.2 \mathrm{mM}$ each $)$ and $10 \mathrm{ul}$ of SYBR Green mix (Roche Co., Basel, Switzerland). Reactions were run on an Light cycler 480 using the universal thermal cycling parameters $\left(95^{\circ} \mathrm{C} 5 \mathrm{~min}\right.$, 45 cycles of $10 \mathrm{sec}$ at $95^{\circ} \mathrm{C}, 20 \mathrm{sec}$ at $60^{\circ} \mathrm{C}$ and $15 \mathrm{sec}$ at $72^{\circ} \mathrm{C}$; melting curve: $10 \mathrm{sec}$ at $95^{\circ} \mathrm{C}, 60 \mathrm{sec}$ at $60^{\circ} \mathrm{C}$ and continues melting). Results were obtained using the sequence detection software Light cycler 480 and analyzed using Microsoft Excel. For all samples melting curves were acquired for quality control purposes. For gene expression quantification, we used the comparative $\mathrm{Ct}$ method. First, gene expression levels for each sample were normalized to the expression level of the housekeeping gene encoding Glyceraldehydes 3-phosphate dehydrogenase (GAPDH) within a given sample $(-\Delta \mathrm{Ct})$; the relative expression of each gene was calculated with $10^{5}{ }^{*} \log 2(-\Delta \mathrm{Ct})$. The difference between the MT-3 over-expression samples compared to the control samples was used to determine the $10^{6}$ ${ }^{*} \log 2(-\Delta \mathrm{Ct})$. Statistical significance of the gene expression difference between the MT-3 over-expression and the control samples was calculated with the Ttest using SPSS 11.5 software.

\section{Statistical analysis}

SPSS v11.5 (SPSS Inc., Chicago, IL) was used for statistical analysis. Data are presented as means \pm standard deviation. Group t-test was used to compare the expression of MT-3 between DMSO group and 5-Aza group. Statistical significance between methylated sample data and clinical pathological features of AML patients were analyzed by Pearson chi-square test or Fisher's exact test. Statistical significance of MT-3 expression among NBM and pediatric AML groups was determined using oneway ANOVA. A p $<0.05$ was considered statistically significant.

\section{Results}

The MT3 promoter is hypermethylated in AML cells

Our long-term research is focused on epigenic modification in pediatric AML and we have found a series of abnormal methylated genes related with AML [29,30]. In this study we conducted CpG island array analysis to explore promoter methylation in pediatric AML. The hypermethylated and hypomethylated genes between AML and NBM were clustered in Figure 1 and Additional file 1 . The results implied that the MT3 promoter was hypermethylated in AML. Subsequent analyses identified four CpG islands in the MT3 promoter region (Figure 2A). Therefore, we conducted an MSP assay in 11 leukemia cell lines using a primer for MSP analysis that encompassed the CpG islands in the MT3 promoter. Our results showed that the MT3 promoter was hypermethylated in $7 / 11$ leukemia cell lines, with the highest methylation levels observed in HL-60, MV4-11 SHI-1, U937 and K562 cells; whereas it was unmethylated in 4/11 cell lines, 697, SHI-1, THP-1 and Jurkat (Figure 2B). To confirm methylation of the MT3 promoter, we treated the leukemia cell lines with 5-Aza. This demethylation reagent is an epigenetic modifier that inhibits DNA methyltransferase activity resulting in hypomethylation and gene activation. PCR analysis showed that methylation status of MT3 was decreased in leukemia cells following 5-Aza treatment compared to control cells treated with DMSO. Our results showed that MT3 expression was significantly upregulated in leukemia cells following 5-Aza treatment compared to control cells treated with DMSO (Figure 2C): MT3 expression was upregulated 39.8 fold in HL-60 cells (24.27 vs. 0.61 , respectively; $P=0.013$ ); and 26.8 fold in MV4-11 cells (34.27 vs. 1.28 , respectively; $P=0.006$ ).

\section{The MT3 promoter was methylated in patients with pediatric AML}

In order to examine the methylation status in the MT3 promoter in pediatric AML, we obtained samples from 41 patients with pediatric AML and 20 control patients with NBM/ITP. Aberrant MT3 methylation was observed in 


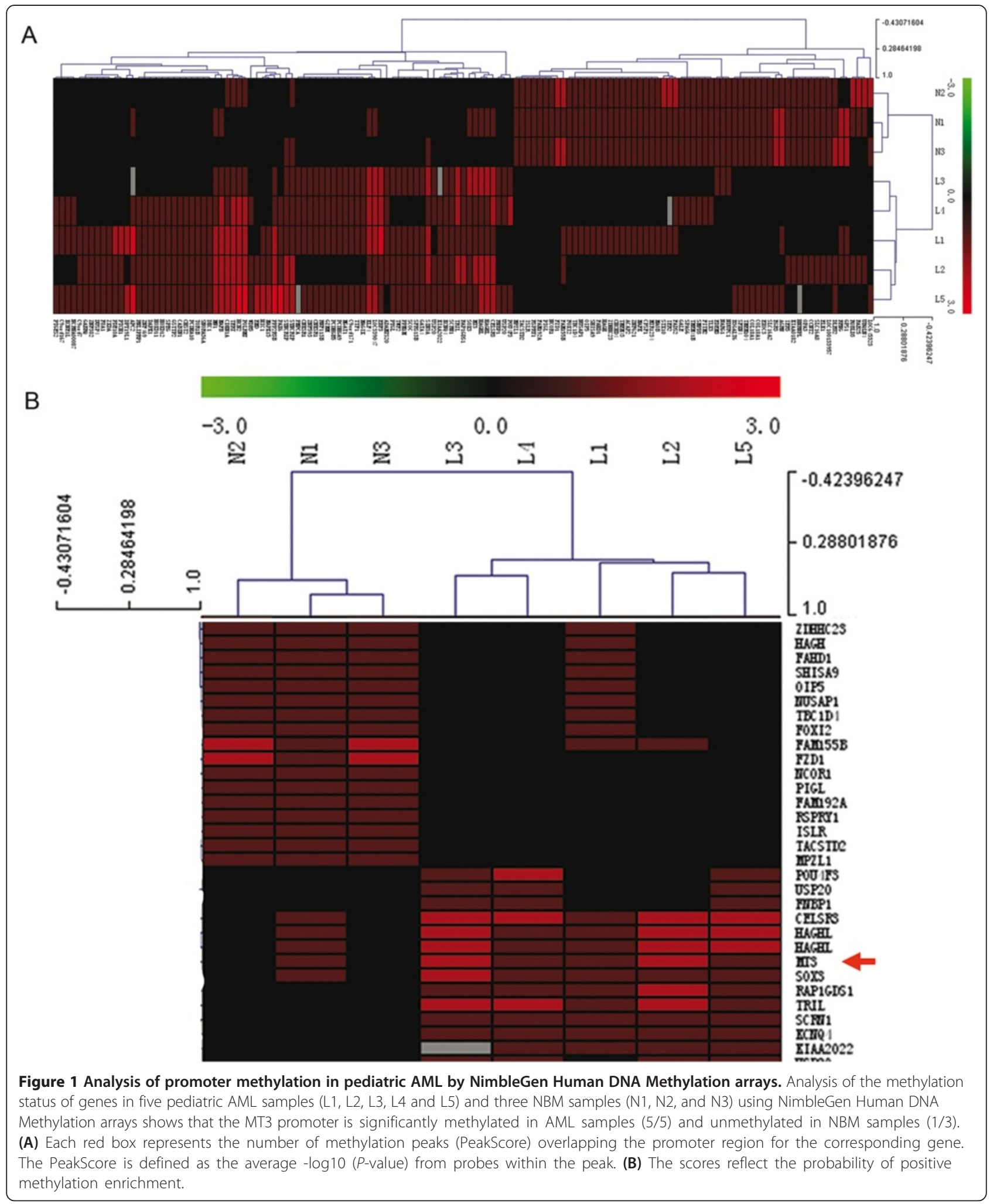


A

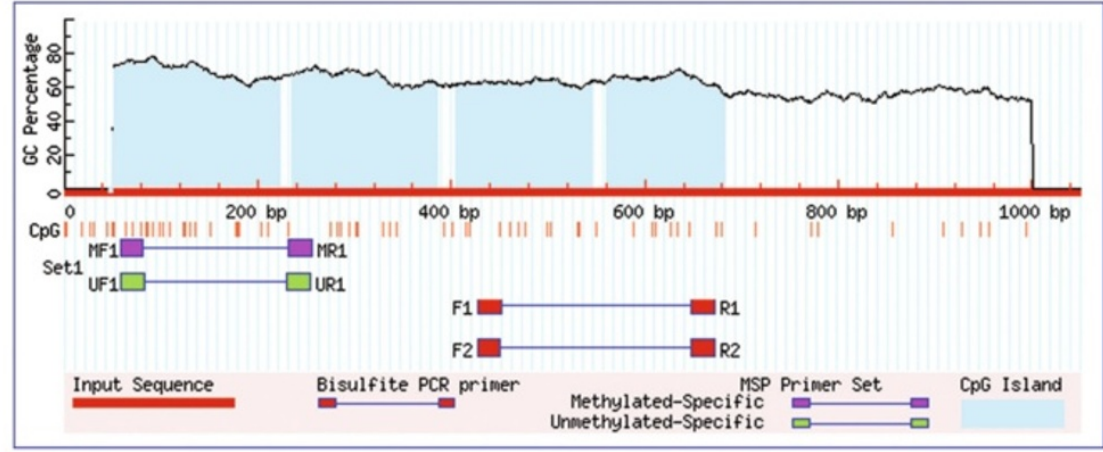

B

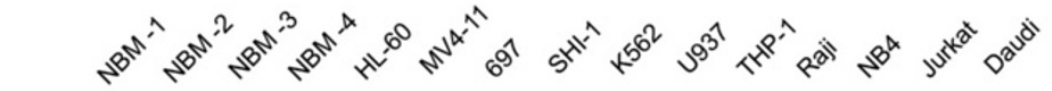

M

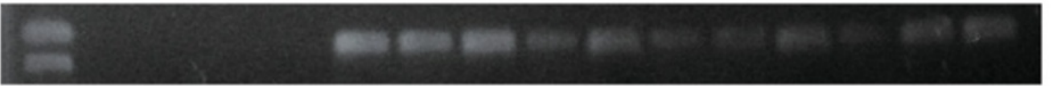

U

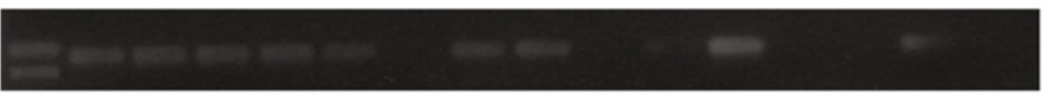

MT-3

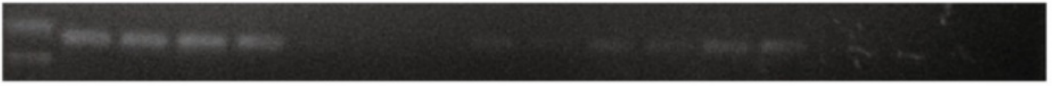

GAPDH

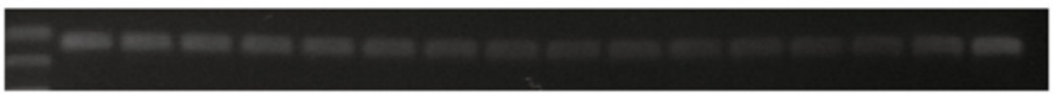

C

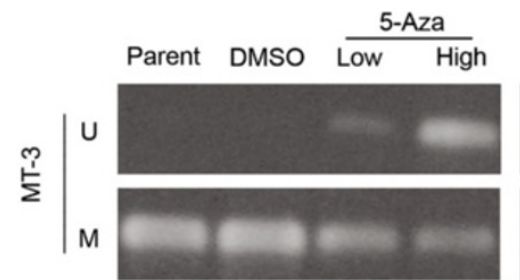

$\mathrm{HL}-60$
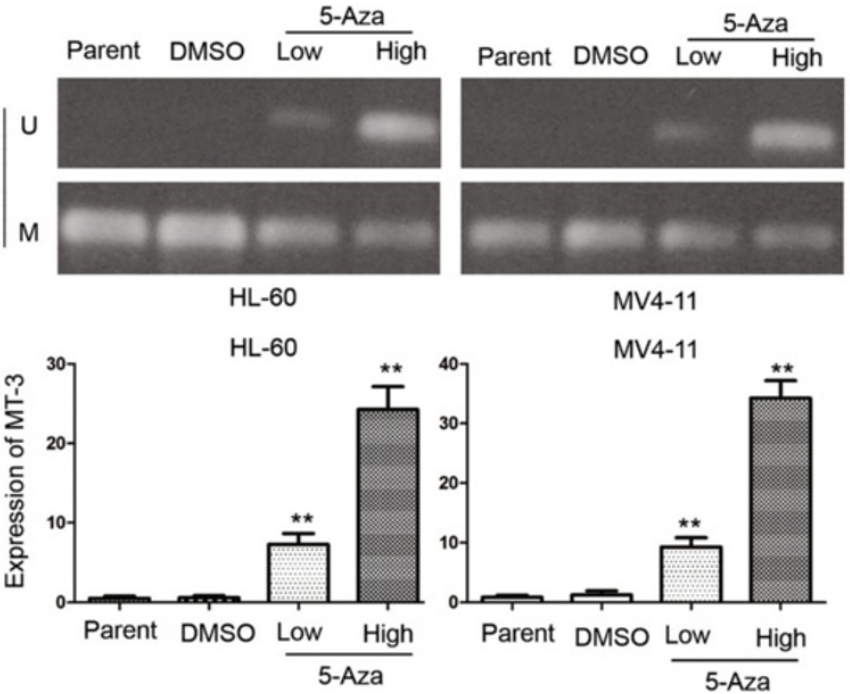

MV4-11

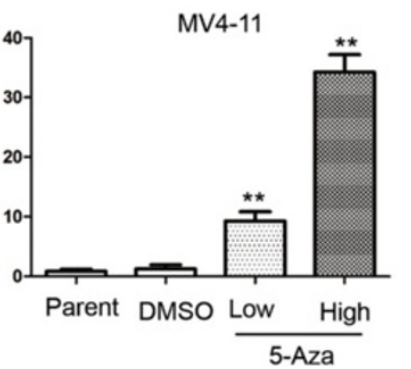

Figure 2 The MT3 promoter is methylated in AML cell lines. (A) Four CpG island regions can be identified in the promoter of MT3. (B) MSP analysis of the methylation status of MT3 in leukemia cell lines shows that the promoter is hypermethylated in 7/11 cell lines. M and $U$ represent MSP results using primer sets for methylated and unmethylated MT3 genes, respectively. (C) PCR analysis showed that methylation status of MT3 was decreased in leukemia cells following 5-Aza treatment compared to control cells treated with DMSO. The transcript level of MT3 is significantly upregulated in HL-60 cells and MV4-11 cells treated with 5-Aza compared to those treated with DMSO. ${ }^{*} P<0.05 ;{ }^{* *} P<0.01$.

$39.0 \%(16 / 41)$ of the pediatric AML samples compared to $10.0 \%(2 / 20)$ of the NBM control samp (Figure 3A). Six NBM samples and six AML samples were selected for further analysis by BGS (Figure 3B). Consistent with the MSP results, these confirmed that the CpG islands in the
MT3 promoter were methylated in the AML samples (68\%-86.7\%); whereas they were unmethylated in the NBM samples (49.3\%-61.3\%).

Examination of the clinicopathologic characteristics in patients with pediatric AML revealed that there were no 
A

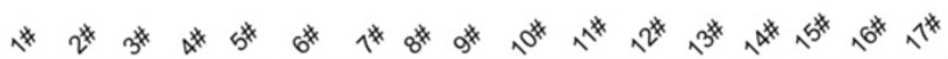

M

U

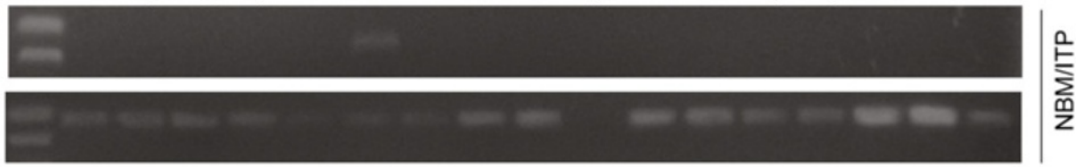

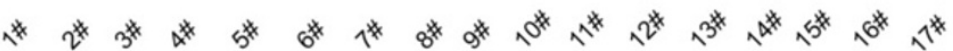

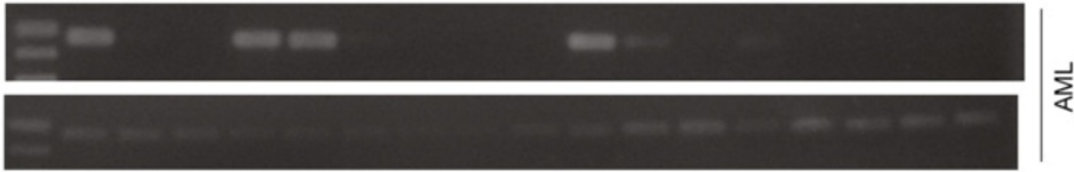

B

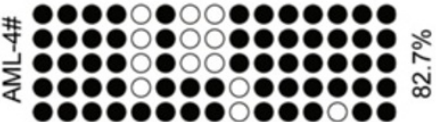

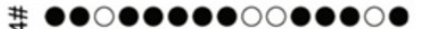

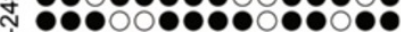

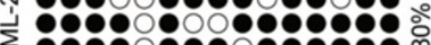

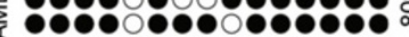

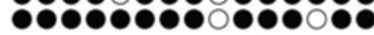

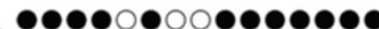

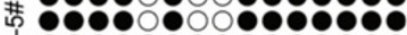

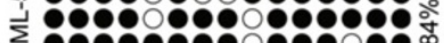

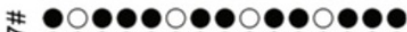

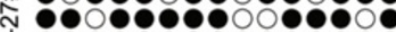

ใดยด

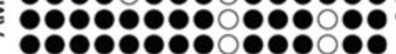

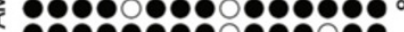

99980

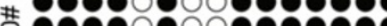

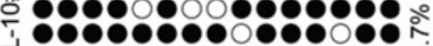

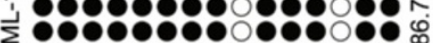

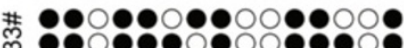

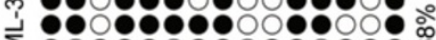

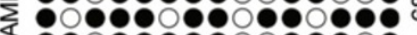

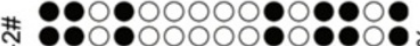

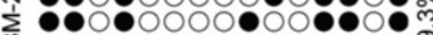

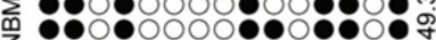

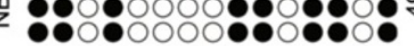

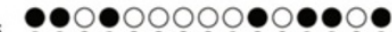

䒨 890800080

๑)

ใด

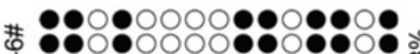

广

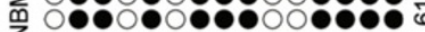

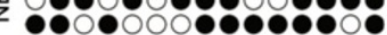

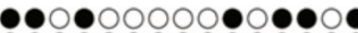

告 8-0

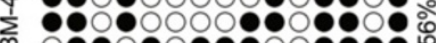

○)ด

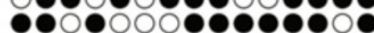
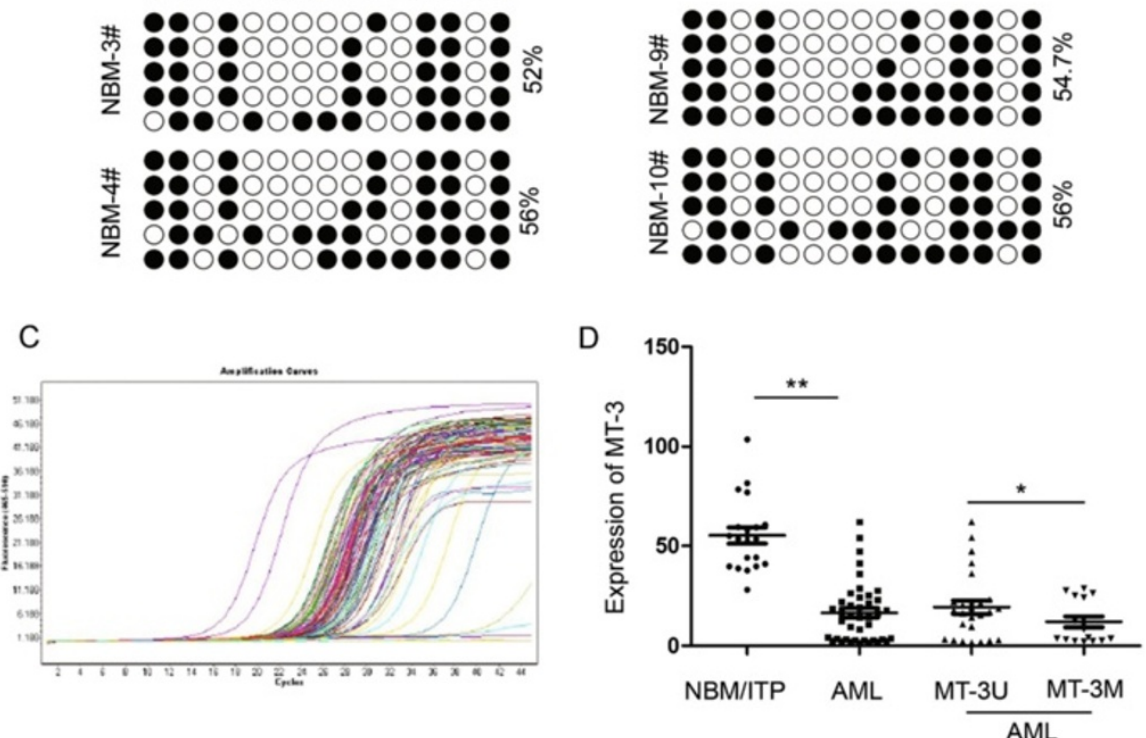

Figure 3 MT3 is inactivated by promoter hypermethylation in AML cell lines. (A) MSP analysis of the methylation status of MT3 shows aberrant methylation in pediatric AML samples compared to NBM/ITP control samples. Aberrant methylation of MT3 was observed in $39.0 \%$ (16/41) of the pediatric AML samples compared to $10.0 \%(2 / 20)$ of the NBM control samples. M and $U$ represent MSP results using primer sets for methylated and unmethylated MT3 genes, respectively. (B) BGS results of three AML samples and three NBM samples show that CpG islands are methylated in the AML samples and unmethylated in the NBM control samples. (C) Real-time PCR analysis of the transcript levels of MT3 in 41 pediatric AML samples and 20 NBM control samples. (D) Quantification shows that MT3 expression is significantly decreased in the AML samples compared to the NBM/ITP control samples. Furthermore, AML patients with methylated MT3 $(n=16)$ show lower MT3 transcript levels than those unmethylated MT3 $(n=25)$. 
A

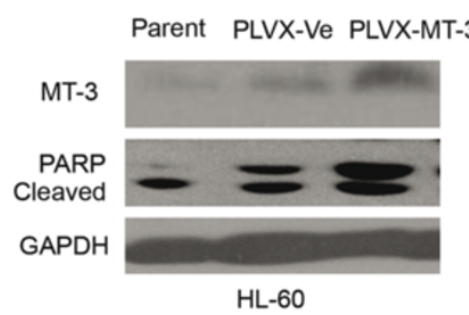

B

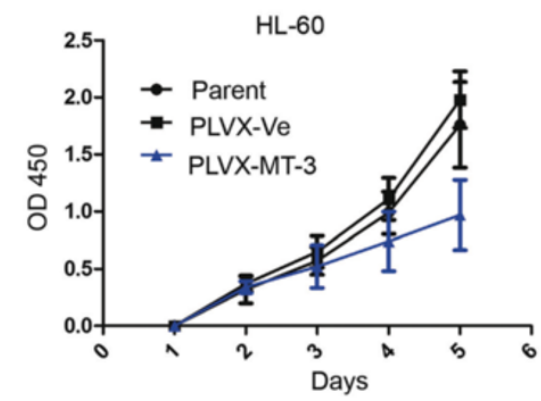

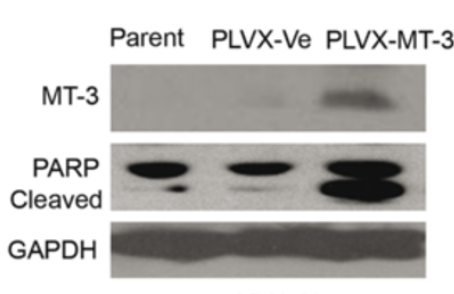

MV4-11

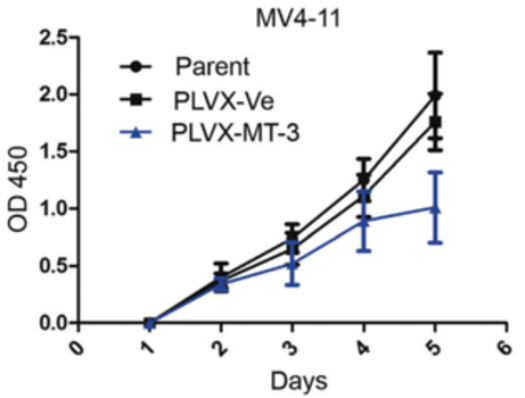

C
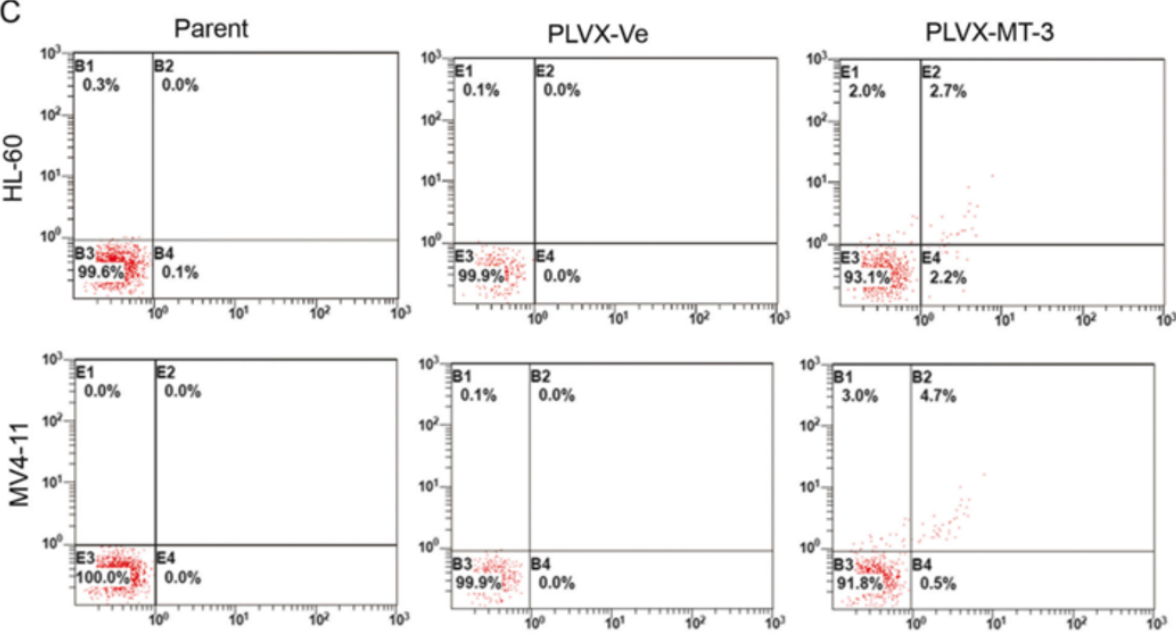

D
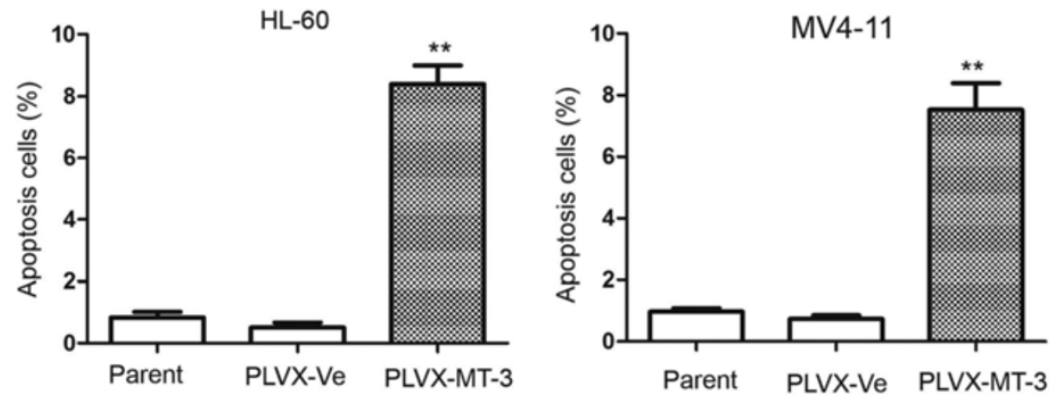

Figure 4 Overexpression of MT3 inhibited proliferation an induced apoptosis in leukemia cells. (A) Transfection with MT3 lentivirus PLVX-MT3 significantly upregulates expression of MT3 in AML cells compared to mock transfected cells. (B) CCK-8 assays show that transfection with MT3 lentivirus inhibits proliferation in HL-60 and MV4-11 cells in a dose-dependent manner compared to mock transfected cells. (C) The number of cells displaying apoptotic features is higher in the HL-60 an MV4-11 cells transfected with PLVX-MT3compared to the mock transfected cells. (D) Quantification shows that the percentage of apoptotic cells in PLVX-MT3 transfected group is significantly higher compared to the percentage in the mock control group. ${ }^{*} P<0.05 ;{ }^{*} P<0.01$. 
A

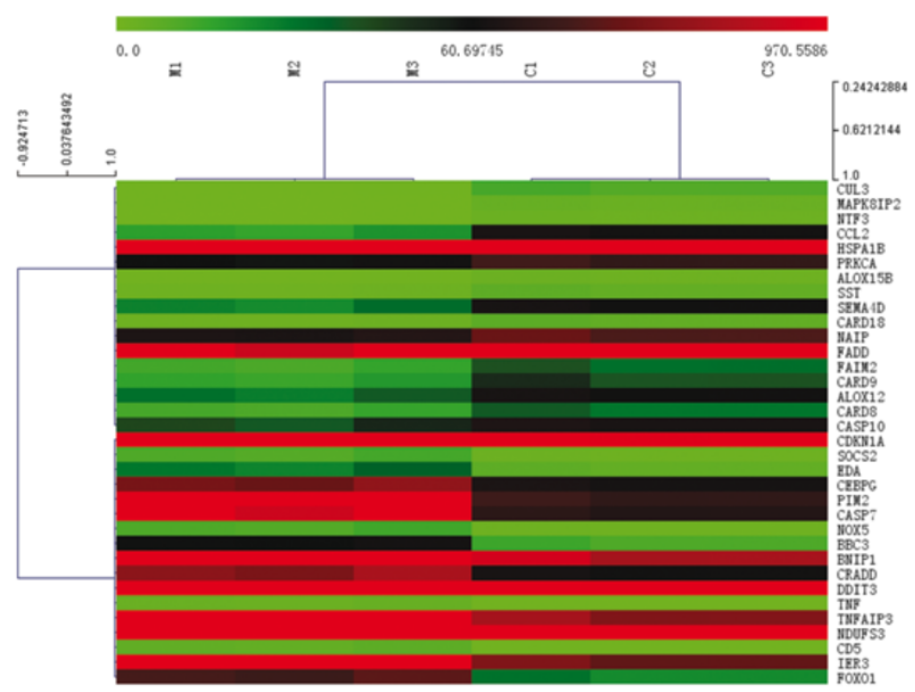

B

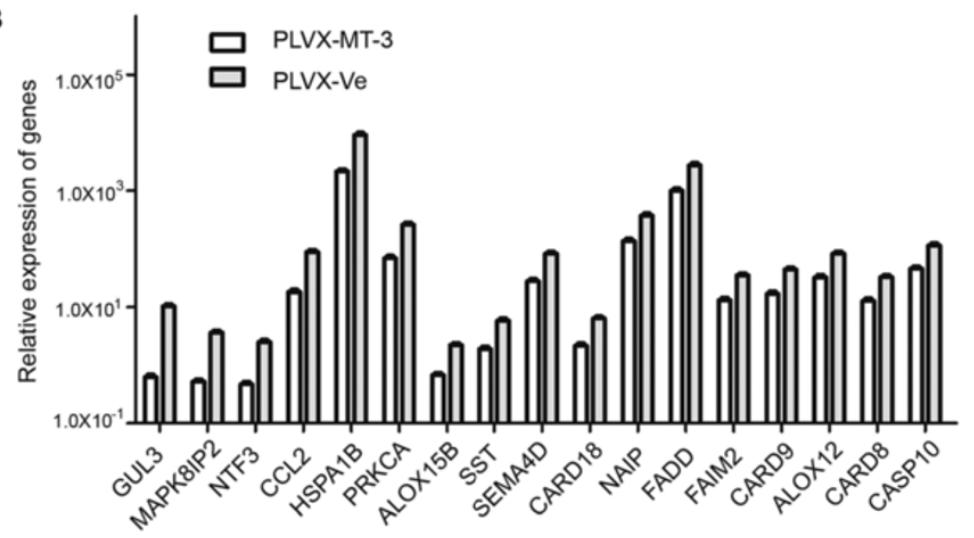

C

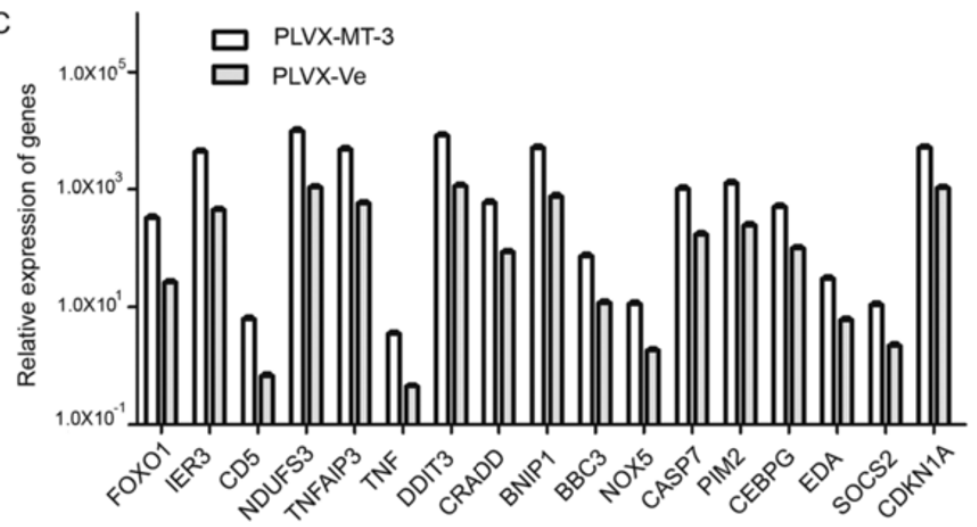

Figure 5 Real-time PCR array analysis showing dysregulated genes implicated in MT3 overexpression. (A) In order to identify genes associated with MT3 overexpression and apoptosis in AML cells, we analyzed and clustered the expressions of 370 key genes involved in apoptosis using the SABioscience Human Apoptosis PCR Array PAHS-3012 kit. (B) Relative expression of the genes most downregulated in MT3-overexpressing AML cells compared to mock transfected cells. (C) Relative expression of the genes most upregulated in MT3-overexpressing cells compared to mock transfected cells.

significant differences in clinical features, such as sex, age, initial hemoglobin level, white blood cell counts, platelet counts and chromosomal abnormalities between those with methylated MT3 and those with unmethylated MT3 (Table 1).
Real-time qPCR was employed to examine the transcript levels of MT3 in the 41 pediatric AML samples and 20 NBM/ITP control samples (Figure 3C; Table 1). MT3 expression was found to be significantly decreased in the AML samples compared to the control samples 
( $16.37 \pm 15.09$ vs. $55.25 \pm 18.34 ; P<0.001)$. Further analysis of the AML samples showed that 16/41 patients with pediatric AML displayed methylated MT3 compared to 25/ 41 patients with unmethylated MT3 (Table 1). Furthermore, those with methylated MT3 showed significantly lower levels of MT3 expression compared to those with unmethylated MT3 (10.65 \pm 10.19 vs. $19.23 \pm 16.93$; $P$ $=0.049$; Figure $3 \mathrm{D}$ ). In summary the hypermethylation status of the MT3 promoter in samples from patients with pediatric AML was consistent with results in human myeloid leukemia cell lines.

\section{Overexpression of MT3 inhibited proliferation and induced apoptosis in leukemia cells}

Transfection of the PLVX-MT3 lentivirus into HL-60 and MV4-11 leukemia cells was found to significantly upregulate expression of MT3 (Figure 4A) and significantly inhibit cell proliferation (Figure 4B). A CCK-8 assay in HL-60 and MV4-11cells showed that the inhibition rate at 5 days post-transfection was $43.7 \pm 30.1 \%$ and $51.1 \pm 26.8 \%$ in MT3-overexpessing cells compared to the mock transfection group $(P<0.05)$.

To determine whether MT3 induced apoptosis in leukemia cells, we performed an Annexin V assay in HL60 and MV4-11 leukemia cells following transfection (Figure 4C and D). The results showed that the proportion of apoptotic cells in the MT3-overexpressing cells (PLVX-MT3) was significantly greater than that in the control group (PLVX-Ve): HL-60 $(8.40 \% \pm 1.04 \%$ vs. $0.5 \% \pm$
$0.3 \%$, respectively; $P=0.003)$; and MV4-11 $(7.53 \% \pm 1.49 \%$ vs. $0.73 \pm 0.21 \%$, respectively; $P=0.014$ ).

To further investigate the apoptotic effect of MT3 in HL-60 and MV4-11 cells, we investigated the expression levels of cleaved PARP, a marker of apoptosis, by Western blotting. The results were consistent with the Annexin V data, confirming that MT3 induced apoptosis in leukemia cells (Figure 4A).

\section{Dysregulation of apoptosis-related genes in HL-60 cells overexpressing MT3}

In order to identify the apoptosis-related genes implicated in MT3 overexpression in HL-60 cells, we analyzed expression and clustering of 370 key genes associated with apoptosis by real-time PCR array analysis, cells harboring empty vector or a vector overexpressing MT3 were subjected to real-time PCR array (Figure 5A). The genes most significantly downregulated or upregulated are shown in Figures $5 \mathrm{~B}$ and $5 \mathrm{C}$, respectively. Examination of the array data revealed that 17 genes were significantly upregulated and 17 genes were significantly downregulated in the MT3-overexpressing group compared to the control group (Tables 2 and 3, respectively). These included TNF (tumor necrosis factor) ligands and their receptors, members of the bcl-2 family, BIRC (baculoviral IAP repeat) domain proteins, CARD (caspase recruitment domain) proteins, death domain proteins, TRAF (TNF receptor-associated factor) domain

Table 2 Genes up regulated in HL-60 cells treated with PLVX-MT-3 compared with control group

\begin{tabular}{|c|c|c|c|c|c|c|}
\hline & Gene & Description & Control & MT-3 & FC & $\mathbf{P}$ \\
\hline 1 & FOXO1 & forkhead box $\mathrm{O} 1$ & 26.4281 & 331.0229 & 12.5254 & 0.010474 \\
\hline 2 & IER3 & immediate early response 3 & 452.3756 & 4374.4713 & 9.6700 & 0.010816 \\
\hline 3 & CD5 & CD5 molecule & 0.6702 & 6.2407 & 9.3121 & 0.010872 \\
\hline 4 & NDUFS3 & NADH dehydrogenase (ubiquinone) Fe-S protein 3 & 1081.0850 & 9828.4023 & 9.0912 & 0.010909 \\
\hline 5 & TNFAIP3 & tumor necrosis factor, alpha-induced protein 3 & 587.6202 & 4806.8271 & 8.1802 & 0.011077 \\
\hline 6 & TNF & tumor necrosis factor & 0.4428 & 3.4995 & 7.9040 & 0.011134 \\
\hline 7 & DDIT3 & DNA-damage-inducible transcript 3 & 1145.0392 & 8216.9381 & 7.1761 & 0.011304 \\
\hline 8 & CRADD & CASP2 and RIPK1 domain containing adaptor with death domain & 86.0764 & 598.6941 & 6.9554 & 0.011361 \\
\hline 9 & BNIP1 & BCL2/adenovirus E1B 19 kDa interacting protein 1 & 763.0465 & 5084.0947 & 6.6629 & 0.011443 \\
\hline 10 & $\mathrm{BBC} 3$ & $\mathrm{BCL} 2$ binding component 3 & 11.7979 & 73.7195 & 6.2486 & 0.01157 \\
\hline 11 & NOX5 & NADPH oxidase, EF-hand calcium binding domain 5 & 1.8139 & 11.2984 & 6.2286 & 0.011576 \\
\hline 12 & CASP7 & caspase 7 , apoptosis-related cysteine peptidase & 172.3255 & 1016.9670 & 5.9014 & 0.011688 \\
\hline 13 & PIM2 & pim-2 oncogene & 247.2885 & 1270.8713 & 5.1392 & 0.012 \\
\hline 14 & CEBPG & CCAAT/enhancer binding protein (C/EBP), gamma & 100.8660 & 510.3751 & 5.0599 & 0.012038 \\
\hline 15 & EDA & ectodysplasin A & 6.0342 & 30.4256 & 5.0422 & 0.012047 \\
\hline 16 & sOCS2 & suppressor of cytokine signaling 2 & 2.1896 & 10.8844 & 4.9710 & 0.012082 \\
\hline 17 & CDKN1A & cyclin-dependent kinase inhibitor $1 \mathrm{~A}$ & 1057.6600 & 5124.4420 & 4.8451 & 0.012147 \\
\hline
\end{tabular}


Table 3 Genes down regulated in HL-60 cells treated with PLVX-MT-3 compared with control group

\begin{tabular}{|c|c|c|c|c|c|c|}
\hline & Gene & Description & Control & MT-3 & FC & $\mathbf{P}$ \\
\hline 1 & CUL3 & cullin 3 & 10.4408 & 0.6273 & 0.0601 & 0.008493 \\
\hline 2 & MAPK8IP2 & mitogen-activated protein kinase 8 interacting protein 2 & 3.6692 & 0.5249 & 0.1431 & 0.009149 \\
\hline 3 & NTF3 & neurotrophin 3 & 2.5110 & 0.4725 & 0.1882 & 0.009344 \\
\hline 4 & CCL2 & chemokine (C-C motif) ligand 2 & 88.1973 & 18.1459 & 0.2057 & 0.009402 \\
\hline 5 & HSPA1B & heat shock $70 \mathrm{kDa}$ protein 1B & 9152.4687 & 2147.2853 & 0.2346 & 0.00949 \\
\hline 6 & PRKCA & protein kinase C, alpha & 259.7601 & 68.8275 & 0.2650 & 0.009593 \\
\hline 7 & ALOX15B & arachidonate 15-lipoxygenase, type B & 2.2320 & 0.6779 & 0.3037 & 0.009776 \\
\hline 8 & SST & somatostatin & 5.9015 & 1.9173 & 0.3249 & 0.009921 \\
\hline 9 & SEMA4D & sema domain, immunoglobulin domain 4D & 82.5241 & 27.6746 & 0.3354 & 0.010009 \\
\hline 10 & CARD18 & caspase recruitment domain family, member 18 & 6.4031 & 2.1791 & 0.3403 & 0.010055 \\
\hline 11 & NAIP & NLR family, apoptosis inhibitory protein & 374.1656 & 136.0874 & 0.3637 & 0.010316 \\
\hline 12 & FADD & Fas (TNFRSF6)-associated via death domain & 2746.1986 & 1001.6552 & 0.3647 & 0.010329 \\
\hline 13 & FAIM2 & Fas apoptotic inhibitory molecule 2 & 34.8320 & 13.2906 & 0.3816 & 0.010573 \\
\hline 14 & CARD9 & caspase recruitment domain family, member 9 & 44.1602 & 16.8715 & 0.3821 & 0.01058 \\
\hline 15 & ALOX12 & arachidonate 12-lipoxygenase & 82.6640 & 32.4829 & 0.3930 & 0.010768 \\
\hline 16 & CARD8 & caspase recruitment domain family, member 8 & 32.5951 & 12.9265 & 0.3966 & 0.010835 \\
\hline 17 & CASP10 & caspase 10 , apoptosis-related cysteine peptidase & 114.4506 & 45.4485 & 0.3971 & 0.010845 \\
\hline
\end{tabular}

proteins, and caspases. FOXO1 was found to be the most upregulated gene in MT3-overexpressing group. The up-regulation of FOXO1 and CDKN1A in MT3overexpressing group was vivificated with western-blot analysis (Figure 6).

\section{Discussion}

In this study, we found that the MT3 promoter was hypermethylated in pediatric AML. Our results showed that the MT3 promoter was hypermethylated in seven out

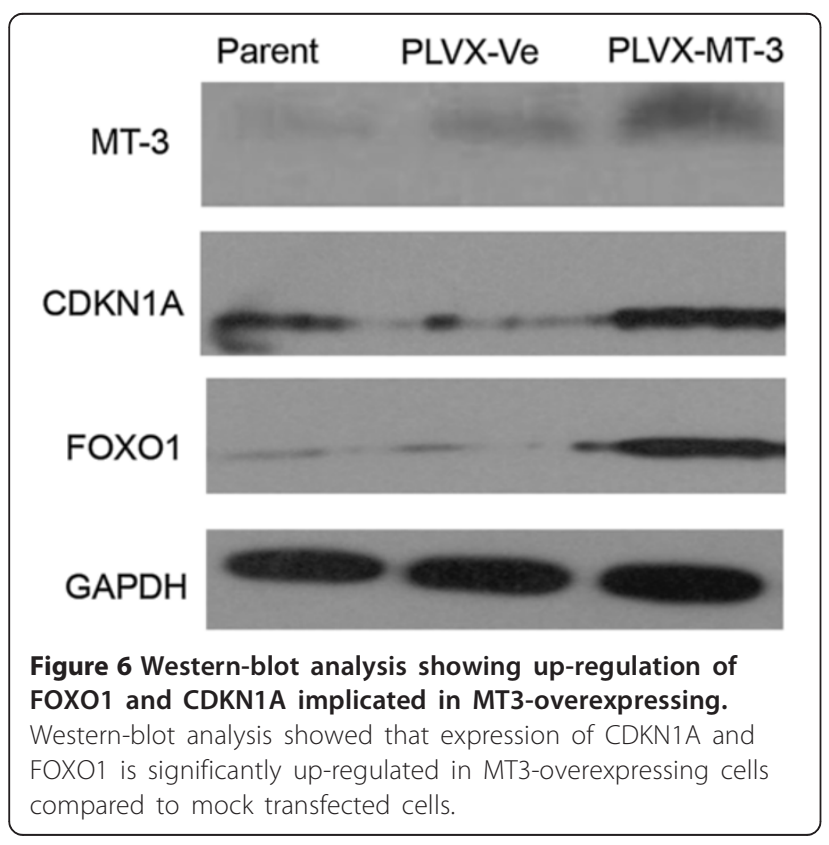

of eleven human myeloid leukemia cell lines. Furthermore, in agreement with reports in esophageal SCC, treatment with 5-Aza, a specific inhibitor of DNA methylation, led to a significant increase in MT3 expression in AML cells (39.8 fold in HL-60 and 26.8 fold in MV4-11; $P<0.05$ and $P<0.01$, respectively). These results demonstrated that the MT3 promoter was consistently significantly methylated in human myeloid leukemia cells, suggesting that the MT3 promoter may also be methylated in pediatric AML.

Consistent with the cell line results, we found that the MT3 promoter was methylated in samples obtained from patients with pediatric AML. Aberrant methylation of MT3 was observed 39.0\% (16/41) of pediatric AML samples compared to $6.7 \%$ (2/30) of NBM control samples. In addition, MT3 was significantly downregulated in the pediatric AML samples compared to the control samples. Further analysis revealed that patients with pediatric AML exhibiting methylated MT3 showed lower levels of MT3 expression compared to those with unmethylated MT3. These results confirmed that hypermethylation of the MT3 promoter occurs with high frequency in both AML cell lines and pediatric AML samples. However, comparisons between the two groups of patients showed no significant differences in MT3 methylation status and patient characteristics, including sex, age, initial hemoglobin level, white blood cell counts, platelet counts, and chromosomal abnormalities. Together, these results implied that various mechanisms may be involved in the downregulation of MT3 in pediatric AML, such as different post-transcriptional modifications, gene deletions, copy number reductions and histone code modifications. 
Further research will be required to elucidate the details of the underlying mechanisms.

A previous study in prostate cancer PC-3 cells revealed that overexpression of MT3 significantly increased cell proliferation, invasion and tumorigenic activities both in vitro and in vivo [31]. However, there were no reports on the role of MT3 in leukemia cells. In this study, we demonstrated that HL-60 and MV4-11 leukemia cells overexpressing MT3 inhibited cell proliferation in a dosedependent manner. Further analysis by Annexin V assay revealed that there were a greater proportion of apoptotic cells in MT3-overexpressing leukemia cells compared to mock transfected cells. The apoptotic effect of MT3 in leukemia cells was confirmed by Western blot analysis which showed that MT3 overexpression led to enhanced expression of cleaved PARP, a marker of apoptosis. These findings suggested that MT3 may possess promising antitumor activity in AML cells.

Real-time PCR array analysis is an effective technique for quantifying the expression of a focused panel of genes $[32,33]$. Therefore, in order to explore the underlying mechanisms of MT3 antitumor activity, we carried out a real-time PCR array assay on 370 apoptosis-related genes in order to identify those genes that were dysregulated in AML following MT3 overexpression. The findings showed that 17 of the genes were significantly upregulated and 17 genes were significantly downregulated in MT3-overexpressing cells relative to control cells. The gene that was most significantly upregulated was found to be FOXO1, which belongs to the family of forkhead box transcription factors. These are downstream targets in the serine/threonine protein kinase B (PKB)/Akt pathway which is involved in the regulation of cell proliferation and survival [34-36]. It has been shown that withdrawal of growth factors leads to inactivation of the PI3K-Akt pathway, FOXO1 dephosphorylation at its Akt sites, nuclear translocation and activation of FOXO target genes [35-37]. FOXO1 plays a central role in initiating apoptosis by inducing expression of death genes, such as FASL. In the nucleus, FOXO1 is a key mediator of tumor suppression downstream of PTEN. Exogenous expression of PTEN induces FOXO1 to relocate to the nucleus, restoring its transcriptional activation. In addition, a constitutively active form of FOXO1 that cannot be phosphorylated by Akt has been found to induce apoptosis in PTEN-null cells, indicating that it has the same effect as reconstitution of PTEN [38]. Our results indicated that FOXO1 is a downstream target of MT3 in pediatric AML. A study in prostate cancer cells suggested that overexpression of FOXO1 resulted in apoptosis via increased expression of TRAIL (TNF-Related Apoptosis-Inducing Ligand) [39]. However, the mechanism and the role of these genes in MT3-induced apoptosis in AML remain to be elucidated.

\section{Conclusions}

In this study, we identified epigenetic inactivation of MT3 in both AML cell lines and pediatric AML samples via hypermethylation of the MT3 promoter. Our findings also showed that transcriptional overexpression of MT3 could inhibit proliferation and induce apoptosis in AML cells. We identified 34 dysregulated apoptosisrelated genes in MT3-overexpressing, including FOXO1. These results may provide new insights into the molecular mechanism of MT3-induced apoptosis; however, further research will be required to determine the underlying details. Together, our findings suggest that MT3 may act as a putative tumor suppressor gene in pediatric AML.

\section{Additional file}

Additional file 1: Analysis of promoter methylation in pediatric AML using NimbleGen Human DNA Methylation 385K Promoter Plus CpG Island Arrays.

\section{Competing interests}

The authors declare that they have no competing interests.

\section{Authors' contributions}

PJ designed and directed the study. TYF and XLX finished the most of experiments. $L Z H$ and WNN finished the real-time PCR array. LYP, XYY, ZWL and $\mathrm{CL}$ collected the leukemia sample. XPF, HSY and $\sqcup J$ collected the clinical information of samples. DXJ and SLC supported the design of primer for BGS and MSP analysis. FF, LG and LYH drafted this manuscript. WJ, FX and NJ participated in study design and coordination, data analysis and interpretation and drafted the manuscript. All authors read and approved the final manuscript.

\section{Acknowledgements}

This work was supported by grants from the National Key Basic Research Program (No. 2010CB933902), the Key Medical Subjects of Jiangsu Province (XK201120), the Innovative Team of Jiangsu Province ( LJ201114, LJ201126 ), the Special Clinical Medical Science and Technology of Jiangsu Province (BL2012050, BL2013014), the Key Laboratory of Suzhou (SZS201108, SZS201307), the National Natural Science Foundation (81100371, 81370627, $81300423,81272143)$, the Natural Science Foundation of Jiangsu Province (No. BK2011308), the Universities Natural Science Foundation of Jiangsu Province (No. 11KJB320014), the Talent's Subsidy Project in Science and Education of Department of Public Health of Suzhou City (No. SWKQ1020), and the Major Scientific and Technological Special Project for "Significant New Drugs Creation" (No. 2012ZX09103301-040).

\section{Author details}

${ }^{1}$ Department of Hematology and Oncology, Children's Hospital of Soochow University, Suzhou, China. ${ }^{2}$ Department of Gastroenterology, the 5th Hospital of Chinese PLA, Yin chuan, China. ${ }^{3}$ Department of Cell and Molecular Biology, Cancer Institute (Hospital), Chinese Academy of Medical Sciences, Peking Union Medical College, Beijing, China. ${ }^{4}$ Translational Research Center, Second Hospital, The Second Clinical School, Nanjing Medical University, Nanjing, China.

Received: 29 April 2014 Accepted: 20 June 2014 Published: 25 June 2014

\section{References}

1. Appelbaum FR, Baer MR, Carabasi MH, Coutre SE, Erba HP, Estey E, Glenn MJ, Kraut EH, Maslak P, Millenson M, Miller CB, Saba HI, Stone R, Tallman MS: NCCN practice guidelines for Acute Myelogenous Leukemia. Oncology (Williston Park) 2000, 14:53-61. 
2. Sanz GF, Sanz MA, Vallespi T, Canizo MC, Torrabadella M, Garcia S, Irriguible D, San Miguel JF: Two regression models and a scoring system for predicting survival and planning treatment in myelodysplastic syndromes: a multivariate analysis of prognostic factors in 370 patients. Blood 1989, 74:395-408.

3. Basu I, Cordovano G, Das I, Belbin TJ, Guha C, Schramm VL: A transition state analogue of 5 '-methylthioadenosine phosphorylase induces apoptosis in head and neck cancers. J Biol Chem 2007, 282:21477-21486

4. Mann MR, Bartolomei MS: Epigenetic reprogramming in the mammalian embryo: struggle of the clones. Genome Biol 2002, 3:2. REVIEWS1003.

5. Agrawal S, Unterberg M, Koschmieder S, ZurStadt U, Brunnberg U, Verbeek W, Buchner T, Berdel WE, Serve H, Muller-Tidow C: DNA methylation of tumor suppressor genes in clinical remission predicts the relapse risk in acute myeloid leukemia. Cancer Res 2007, 67:1370-1377.

6. Akhavan-Niaki H, Samadani AA: DNA methylation and cancer development: molecular mechanism. Cell Biochem Biophys 2013, 67:501-513.

7. Gaudet F, Hodgson JG, Eden A, Jackson-Grusby L, Dausman J, Gray JW, Leonhardt $\mathrm{H}$, Jaenisch R: Induction of tumors in mice by genomic hypomethylation. Science 2003, 300:489-492.

8. Chen RZ, Pettersson U, Beard C, Jackson-Grusby L, Jaenisch R: DNA hypomethylation leads to elevated mutation rates. Nature 1998, 395:89-93.

9. Worm J, Aggerholm A, Guldberg P: In-tube DNA methylation profiling by fluorescence melting curve analysis. Clin Chem 2001, 47:1183-1189.

10. Willman CL: Targeted AML therapy: new biologic paradigms and therapeutic opportunities. Leukemia 2001, 15:690-694

11. Toyota M, Kopecky KJ, Toyota MO, Jair KW, Willman CL, Issa JP: Methylation profiling in acute myeloid leukemia. Blood 2001, 97:2823-2829.

12. Miftakhova R, Sandberg T, Hedblom A, Nevzorova T, Persson $J$, Bredberg A: DNA methylation in ATRA-treated leukemia cell lines lacking a PML-RAR chromosome translocation. Anticancer Res 2012, 32:4715-4722.

13. Fu L, Huang $W$, Jing $Y$, Jiang $M$, Zhao $Y$, Shi J, Huang $S$, Xue $X$, Zhang $Q$, Tang J, Dou L, Wang L, Nervi C, Li Y, Yu L: AML1-ETO triggers epigenetic activation of early growth response gene $I$, inducing apoptosis in $t(8 ; 21)$ acute myeloid leukemia. Febs J 2013, 281:1123-1131.

14. Deshpande AJ, Bradner J, Armstrong SA: Chromatin modifications as therapeutic targets in MLL-rearranged leukemia. Trends Immunol 2012 33:563-570

15. Bernt KM, Armstrong SA: Targeting epigenetic programs in MLLrearranged leukemias. Hematology Am Soc Hematol Educ Program 2011, 2011:354-360

16. Tabe Y, Konopleva M, Kondo Y, Contractor R, Jin L, Ruvolo V, Tsutsumi-Ishii Y, Miyake K, Miyake N, Ohsaka A, Nagaoka I, Issa JP, Andreeff M: PML-RARalpha and AML1-ETO translocations are rarely associated with methylation of the RARbeta2 promoter. Ann Hematol 2006, 85:689-704

17. Haferlach T, Nagata Y, Grossmann V, Okuno Y, Bacher U, Nagae G, Schnittger S, Sanada M, Kon A, Alpermann T, Yoshida K, Roller A, Nadarajah N, Shiraishi Y, Shiozawa Y, Chiba K, Tanaka H, Koeffler HP, Klein HU, Dugas M, Aburatani H, Kohlmann A, Miyano S, Haferlach C, Kern W, Ogawa S: Landscape of genetic lesions in 944 patients with myelodysplastic syndromes. Leukemia 2014, 28:241-247.

18. Weissmann S, Alpermann T, Grossmann V, Kowarsch A, Nadarajah N, Eder C, Dicker F, Fasan A, Haferlach C, Haferlach T, Kern W, Schnittger S, Kohlmann A: Landscape of TET2 mutations in acute myeloid leukemia. Leukemia 2012, 26:934-942.

19. Ajjimaporn A, Swinscoe J, Shavali S, Govitrapong P, Ebadi M: Metallothionein provides zinc-mediated protective effects against methamphetamine toxicity in SK-N-SH cells. Brain Res Bull 2005, 67:466-475.

20. Howells C, West AK, Chung RS: Neuronal growth-inhibitory factor (metallothionein-3): evaluation of the biological function of growthinhibitory factor in the injured and neurodegenerative brain. Febs $J$ 2010, 277:2931-2939.

21. Ma F, Wang H, Chen B, Wang F, Xu H: Metallothionein 3 attenuated the apoptosis of neurons in the CA1 region of the hippocampus in the senescence-accelerated mouse/PRONE8 (SAMP8). Arq Neuropsiquiatr 2011, 69:105-111.

22. Carrasco J, Penkowa M, Giralt M, Camats J, Molinero A, Campbell IL, Palmiter $\mathrm{RD}$, Hidalgo J: Role of metallothionein-III following central nervous system damage. Neurobiol Dis 2003, 13:22-36.
23. Lee SJ, Koh JY: Roles of zinc and metallothionein-3 in oxidative stressinduced lysosomal dysfunction, cell death, and autophagy in neurons and astrocytes. Mol Brain 2010, 3:30.

24. Lowy AM, Clements WM, Bishop J, Kong L, Bonney T, Sisco K, Aronow B, Fenoglio-Preiser C, Groden J: beta-Catenin/Wnt signaling regulates expression of the membrane type 3 matrix metalloproteinase in gastric cancer. Cancer Res 2006, 66:4734-4741.

25. Smith E, Drew PA, Tian ZQ, De Young NJ, Liu JF, Mayne GC, Ruszkiewicz AR, Watson DI, Jamieson GG: Metallothionien 3 expression is frequently down-regulated in oesophageal squamous cell carcinoma by DNA methylation. Mol Cancer 2005, 4:42.

26. Deng D, El-Rifai W, Ji J, Zhu B, Trampont P, Li J, Smith MF, Powel SM: Hypermethylation of metallothionein-3 CpG island in gastric carcinoma. Carcinogenesis 2003, 24:25-29.

27. Olek A, Oswald J, Walter J: A modified and improved method for bisulphite based cytosine methylation analysis. Nucleic Acids Res 1996, 24:5064-5066.

28. Cheng Y, Geng H, Cheng SH, Liang P, Bai Y, Li J, Srivastava G, Ng MH, Fukagawa T, Wu X, Chan AT, Tao Q: KRAB zinc finger protein ZNF382 is a proapoptotic tumor suppressor that represses multiple oncogenes and is commonly silenced in multiple carcinomas. Cancer Res 2010, 70:6516-6526.

29. Yan-Fang $T$, Jian N, Jun L, Na W, Pei-Fang X, Wen-Li Z, Dong W, Li P, Jian W, Xing F, Jian P: The promoter of miR-663 is hypermethylated in Chinese pediatric acute myeloid leukemia (AML). BMC medical genetics 2013, 14:74

30. Jian P, Li ZW, Fang TY, Jian W, Zhuan Z, Mei LX, Yan WS, Jian N: Retinoic acid induces $\mathrm{HL}-60$ cell differentiation via the upregulation of miR-663. J Hematol Oncol 2011, 4:20.

31. Juang HH, Chung LC, Sung HC, Feng TH, Lee YH, Chang PL, Tsui KH: Metallothionein 3: an androgen-upregulated gene enhances cell invasion and tumorigenesis of prostate carcinoma cells. Prostate 2013, 73:1495-1506.

32. Yan-Fang T, Dong W, Li P, Wen-Li Z, Jun L, Na W, Jian W, Xing F, Yan-Hong $L$, Jian N, Jian P: Analyzing the gene expression profile of pediatric acute myeloid leukemia with real-time PCR arrays. Cancer Cell Int 2012, 12:40.

33. Tao YF, Lu J, Du XJ, Sun LC, Zhao X, Peng L, Cao L, Xiao PF, Pang L, Wu D, Wang N, Feng $X, L i$ YH, Ni J, Wang J, Pan J: Survivin selective inhibitor YM155 induce apoptosis in SK-NEP-1 Wilms tumor cells. BMC Cancer 2012, 12:619.

34. Zhang X, Tang N, Hadden TJ, Rishi AK: Akt, FoxO and regulation of apoptosis. Biochim Biophys Acta 1813, 2011:1978-1986.

35. Lu H, Huang H: FOXO1: a potential target for human diseases. Curr Drug Targets 2011, 12:1235-1244.

36. Monsalve M, Olmos Y: The complex biology of FOXO. Curr Drug Targets 2011, 12:1322-1350.

37. Fu Z, Tindall DJ: FOXOs, cancer and regulation of apoptosis. Oncogene 2008, 27:2312-2319.

38. Modur $V$, Nagarajan $\mathrm{R}$, Evers BM, Milbrandt J: FOXO proteins regulate tumor necrosis factor-related apoptosis inducing ligand expression. Implications for PTEN mutation in prostate cancer. J Biol Chem 2002, 277:47928-47937.

39. Nakamura N, Ramaswamy S, Vazquez F, Signoretti S, Loda M, Sellers WR: Forkhead transcription factors are critical effectors of cell death and cell cycle arrest downstream of PTEN. Mol Cell Biol 2000, 20:8969-8982.

doi:10.1186/1479-5876-12-182

Cite this article as: Tao et al:: Metallothionein III (MT3) is a putative tumor suppressor gene that is frequently inactivated in pediatric acute myeloid leukemia by promoter hypermethylation. Journal of Translational Medicine 2014 12:182 